\title{
Decadal change of the East Asian summer monsoon and its related surface temperature in Asia-Pacific during 1880-2004
}

\author{
LIN Xiang, ZHU CongWen* \& LÜ JunMei \\ Institute of Climate System, Chinese Academy of Meteorological Sciences, Beijing 100081, China
}

Received January 21, 2013; accepted May 23, 2013; published online July 16, 2013

\begin{abstract}
The East Asian summer monsoon (EASM) and its related change of surface temperature in the past century were not clearly addressed due to absence of atmospheric reanalysis data before 1948. On the benchmark of station-observed sea level pressure (SLP) in China, we utilized multiple SLP datasets and evaluated their qualities in measuring the SLP-based EASM index (EASMI). It is found that the EASMI based on the SLP of the Hadley center version 2 (HadSLP2) has shown the best performance on the interannual and decadal time scales. Instead of showing a linear weakening trend pointed out by the previous study, the EASMI has likely exhibited the decadal variability, characterized by weakened trends during 1880-1906, 1921-1936, and 1960-2004, and with enhanced trends during 1906-1921 and 1936-1960, respectively. Corresponding to the weakened and enhanced periods of EASMI since the 1920s, the surface air temperature (SAT) index (SATI) averaged in eastern China has likely shown a warming and a cooling trend, respectively. However, the decadal abrupt transitions between the two indices do not occur concurrently, which results in a weak correlation between two indices on the decadal time scale. Further analysis indicates that there are four key regions where the SAT is significantly correlated with the EASMI, suggesting the joint impact of surface temperature in Asia-Pacific on the EASM during 1880-2004. In which, the decadal change of SAT near the Lake Baikal plays an important role in the linear trends of the EASM before and after 1960.
\end{abstract}

East Asian summer monsoon, surface temperature, decadal change, monsoon, trend

Citation: Lin X, Zhu C W, Lü J M. Decadal change of the East Asian summer monsoon and its related surface temperature in Asia-Pacific during 1880-2004. Chin Sci Bull, 2013, 58: 4497-4503, doi: 10.1007/s11434-013-5969-x

The East Asian summer monsoon (EASM) has witnessed weakened southwesterly winds over the northern East Asia with the persistent drought in the North China and the wet climate in South China since the late 1970s [1-6]. A number of studies attribute this weakened trend of EASM to the change of large-scale thermal variations in the Asia-Pacific region, such as the cooling trend in the upper troposphere in East Asia during July and August [3], the increase of snow cover over the Tibetan Plateau and sea surface temperature (SST) over the tropical Indian Ocean and western North Pacific [4], the reduced temperature difference between the northern and southern China [5], and the increase of surface air temperature (SAT) over the region of Lake Baikal as well [6]. However, these works mainly focus on the linear

*Corresponding author (email: tomzhu@ @ams.cma.gov.cn) trend of EASM in recent decades. The relationship between the EASM and the large-scale thermal condition over the first half of the 20th century has not been clearly addressed due to the absence of atmosphere reanalyzed data before 1948.

In contrast to the other atmospheric variables, sea level pressure (SLP) has a long record in observations, therefore, the SLP-based EASM index (EASMI) has been widely applied to measure the long-term variation of EASM [7-11]. Previous studies suggest that the summer monsoon is generally stronger during the global warm periods [12] and the eastern China suffers a warmer summer when a strong EASM occurs [8], it implies that the variation of SAT in eastern China may represent the change of EASM intensity to some extent. The IPCC report indicates that the EASM index (EASMI) has shown a robust weakening trend since 
the 1920s [11]. However, the observed time series of SAT anomalies in eastern China exhibited two warm (19201940s and after the 1980s) and two cold periods (19001920s and 1950-1970s) over the past century [13]. Why the change of SAT in eastern China shows a distinct decadal variability while the time series of EASMI mainly exhibit a weakening trend? The aim of this study is to discuss the decadal variation of the EASM and its possible relationship with the large-scale variation of surface temperature in Asia-Pacific region over the past century.

\section{Data and methods}

In the present study, we utilized SLP datasets from the National Center for Environmental Prediction/National Center for Atmospheric Research Reanalysis (NCEP/NCAR) [14], the ECMWF 40-year Reanalysis (ERA-40) [15], the new version of SLP in the Hadley centre (HadSLP2) [16], and the second version of the 20th Century Reanalysis (20CR) [17], respectively. These SLP datasets cover the time period of 1871-2008. In which, the HadSLP2 and the 20CR are the newly released dataset with more station-observed information. In addition, we used 33 station-observed SLP around $105^{\circ}-115^{\circ} \mathrm{E}$ between $20^{\circ}$ and $50^{\circ} \mathrm{N}$ to verify the reanalyzed SLP datasets in China during 1958-2010. The utilized SAT in eastern China is derived from Wang et al. $[13,18]$, which contains 71 station-observed SAT series in the east of $100^{\circ} \mathrm{E}$ in China and spans the time period of 1880-2010. Here we defined the averaged SAT index (SATI) during boreal summer (June-August) and used it to measure the thermal variation in eastern China. Besides, the global surface temperature is jointly combined by the land SAT from CRU Ts 3.1 [19] and the SST from Hadley centre (HadISST) [20] in order to reduce the missing data during the early decades in the Asia-Pacific.

Finding an overall linear trend is a common method in scientific studies. It is almost a requirement when one intends to study variability. Nevertheless, when dealing with long climate temporal series, only a straight fitting line seldom has any relevant meaning for decadal variability. Therefore, in the present study, we apply a method of piecewise linear fitting (PLF) [21,22] to figure out the linear trend of EASMI and the SAT index in eastern China. The PLF uses a least-squares approach to compute a continuous set of straight lines that best fit a given time series, subject to a number of constraints on the minimum distance between breakpoints and on the minimum trend change at each breakpoint. The method is far richer than simple linear trend analysis or spectral analysis, as it allows for the evaluation of nonmonotonic and non-periodic climate oscillations. Compared with the other methods, the PLF method does not need to give the number of turning points in advance. The positions of breakpoints and decadal trends computed in such a way would be more reasonable. Besides, the $F$-test is also applied to verify the change of variance in the time series of EASMI in the present study [23].

\section{Decadal change of the EASM}

Many indices have been developed to measure the EASM variability [24-27]. However, few of them can be applied to discuss the long-term variability of the EASM due to the atmospheric parameters, such as the observed low-level winds were not available before the 1950s. In the present study, the EASMI is defined by the difference of the averaged SLP between the longitude of $110^{\circ}$ and $160^{\circ} \mathrm{E}$ from $20^{\circ}$ to $50^{\circ} \mathrm{N}$ (SLP $160^{\circ} \mathrm{E}$ minus SLP1 $10^{\circ} \mathrm{E}$ ) during summer [9-11], and it is calculated using SLP which is available for both observation and reanalysis in the early decades.

Although the EASMI utilized in the present study is fully determined by the land-sea SLP difference over the AsiaPacific region, this EASMI has shown a good performance in identifying the main characteristics of the EASM. Figure 1 shows correlation coefficients between the EASMI and summer precipitation, SAT, SLP and the winds at $850 \mathrm{hPa}$ over East Asia during 1979-2010. The results suggest that the strong EASMI is characterized by more precipitation in Northeast China, the Yellow River valley, the western North Pacific regions, and less precipitation in the south of Yangtze River valley (Figure 1(a)). The EASMI bears a positive correlation with the SAT in the upper-stream of Yangtze River valley, and it exhibits significantly negative correlations with the SAT around the Lake Baikal and the regions in the south of Japan. Therefore, the enhanced EASMI is characterized by warmer SAT and lower SLP anomalies in central parts of eastern China, and colder SAT and the lower SLP anomalies around the Lake Baikal (Figure 1(b), (c)). In addition, the enhanced EASMI exhibits a large-scale cyclonic anomaly circulation prevailing over the Asia-Pacific region with the enhanced southwesterly winds in the western North Pacific and a stronger northeasterly winds dominant in the east of the Lake Baikal (Figure 1(c), (d)). Therefore, the interannual variability of EASMI can indicate the large-scale summer circulation in the AsiaPacific region.

However, we note that the time series of EASMI based on the different sources of SLP has exhibited quite different characteristics. Figure 2(a) shows the interannual variations of EASMI and the SLP indices at $110^{\circ}$ and $160^{\circ} \mathrm{E}$ during 1880-2010, which is calculated by using HadSLP2, NCEP/ NCAR, ERA40, and the 20CR, respectively. It is clearly observed that the NCEP/NCAR-based EASMI shows a large value before 1965 and a decreasing trend since the 1950 s, which exhibits greater interdecadal variability than the other counterparts. The ERA40-based EASMI indicates less decadal variability with a weak decreasing trend. In addition, the EASMI based on the HadSLP2 and the 20CR also exhibit different variability after 1940s. Therefore, the EASMI based on the different datasets show quite different 

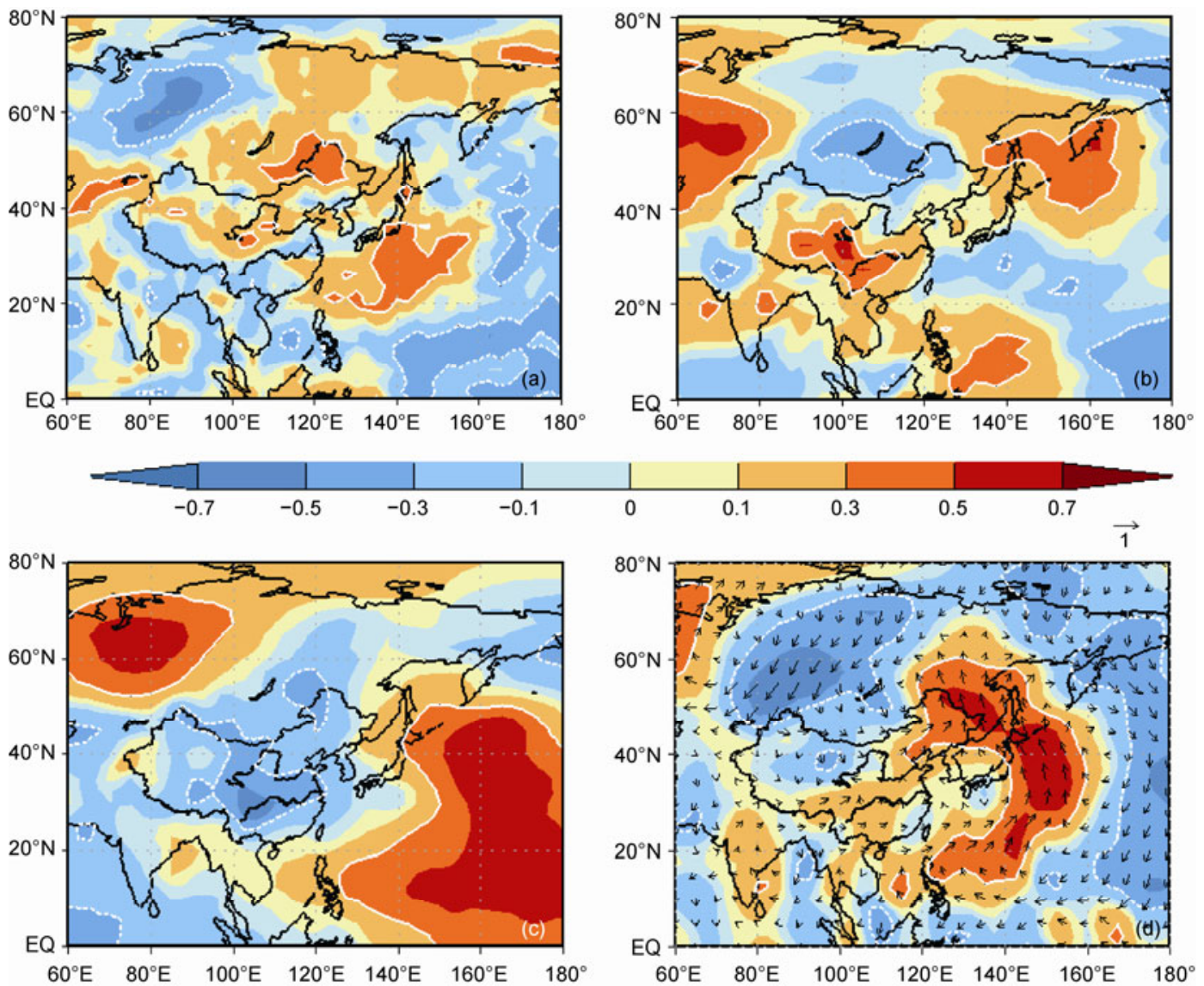

Figure 1 Correlation coefficients between the EASMI and (a) precipitation, (b) surface air temperature, (c) SLP and (d) winds speed (shaded) and wind field (vector) at $850 \mathrm{hPa}$ in summer during 1979-2010. The region enclosed by the white line indicates the correlation coefficients statistically significant at the 0.05 level.
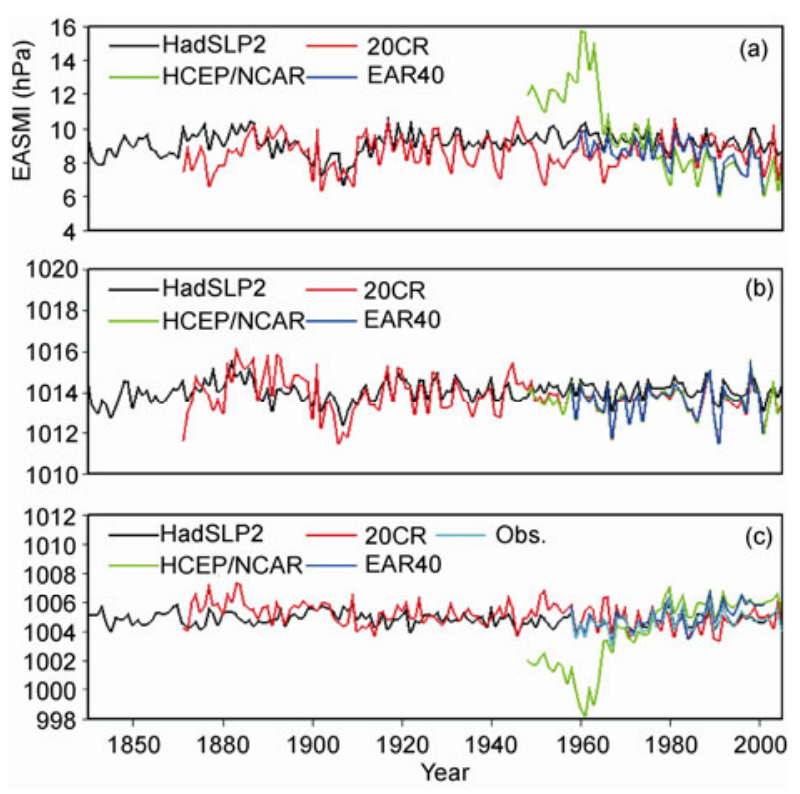

Figure 2 The time series of (a) EASMI, the SLP index along the longitude of (b) $160^{\circ} \mathrm{E}$ and (c) $110^{\circ} \mathrm{E}$ averaged between $20^{\circ}-50^{\circ} \mathrm{N}$ on the basis of multiple SLP datasets during 1850-2004 (unit: hPa). decadal variability. It is observed that the time series of the SLP index at the longitude of $160^{\circ} \mathrm{E}$ show the relatively consistent features in these data sources (Figure 2(b)), therefore, the difference of EASMI mainly comes from the SLP index at the longitude of $110^{\circ} \mathrm{E}$ (Figure 2(c)). For instance, the NCEP/NCAR-based EASMI exhibits a large departure away from the observed counterpart and shows large interdecadal variability due to the biases over the Eurasian continents according to the past studies [6,28-30].

We compared the SLP indices at $110^{\circ} \mathrm{E}$ with the 33 station-observed SLP index around $110^{\circ} \mathrm{E}$ in eastern China. The result suggests that the HadSLP2-based SLP index at $110^{\circ} \mathrm{E}$ is closest to the observation during 1958-2010 (Figure 2(c)). The 20CR-based SLP index is greater than the observation after the 1980s. In contrast, the SLP index from ERA40 and HadSLP2 exhibit a consistent decreasing trend during the recent decades. Table 1 shows the correlation coefficients and the root mean square difference (RMSD) of the SLP index at $110^{\circ} \mathrm{E}$ between the observation and NCEP/ NCAR, ERA40, HadSLP2 and 20CR. The correlation coefficients are 0.57, 0.82, 0.97, and 0.48 during 1958-2001, and the RMSD between the observation and the HadSLP2 
Table 1 Comparison between the multiple SLP datasets and the observations at $110^{\circ} \mathrm{E}^{\mathrm{a})}$

\begin{tabular}{lcc}
\hline \multicolumn{1}{c}{ Dataset } & Correlation coefficient & RMSD \\
\hline NCEP & $0.57^{*}$ & $1958-2001$ \\
ERA-40 & $0.82^{*}$ & 2.19 \\
HadSLP2 & $0.97^{*}$ & 0.56 \\
20th century reanalysis & $0.48^{*}$ & 0.22 \\
\hline & & 0.76 \\
NCEP & $0.94^{*}$ & \\
ERA-40 & $0.70^{*}$ & 1.02 \\
HadSLP2 & $0.97 *$ & 0.72 \\
20th century reanalysis & $0.61^{*}$ & 0.20 \\
\hline
\end{tabular}

a) The correlation coefficient and the root mean square difference (RMSD, unit: $\mathrm{hPa}$ ) between SLP from multiple global datasets and station observations at the longitude of $110^{\circ} \mathrm{E}$ averaged for $20^{\circ}-50^{\circ} \mathrm{N}$. * indicates the correlation coefficients significant at 0.01 level.

exhibits the minimum of 0.22 in contrast to the other counterparts. The correlation coefficient is $0.94,0.70,0.97$, and 0.61 during 1979-2001, and the RMSD between the observation and the HadSLP2 also exhibits the minimum of 0.20 , compared with the other datasets. When we removed the interannual signals by using 13 weights filter, the correlation coefficients become $0.87,0.73,0.98$, and -0.52 , respectively. All of the above correlation coefficients passed the 0.01 significant level of Monte Carlo test, but for the time series of 20CR which bears a negative correlation with the observation. Such results suggest that the HadSLP2based SLP index at $110^{\circ} \mathrm{E}$ is much closer to the observation whatever on the interannual or the decadal time scales. Therefore, the EASMI in the present study is calculated by the HadSLP2 SLP.

The IPCC report shows that the variation of the EASMI exhibits a weakening trend since the 1920s [11]. In our result, the EASMI calculated by the HadSLP2 exhibits the smaller negative anomalies after the 1990s and the greater positive anomalies between 1960-1970s, and it shows considerable decadal variability after the 1920s (Figure 3(a)). Therefore, the observed linear weakening trend of EASMI in the IPCC report did not correctly indicate the long-term variation of EASMI due to the SLP data biases. Such a result guides us to get the image that the change of SAT in eastern China shows a distinct decadal variability, but the time series of EASMI mainly exhibit a weakening trend.

In fact, the EASMI also shows a multi-decadal variability (20-70 years) instead of the linear trend during the whole time period. The $F$-test indicated that the variance of EASMI exhibits obvious difference during the time periods before 1918, 1919-1950 and after 1951 corresponding to the different levels of the sample sizes (number of observation) of HadSLP2 (not shown), which increased extraordinarily with the time (not shown). Therefore, the amplitudes of the EASMI during the different time period are difficult to be compared, due to the variance shift. To avoid such uncertainty, in the present study, the decadal variability of EASMI is described by the decadal trends between two neighboring breakpoints in the time series (Figure 3(c)).

\section{Relationship between EASMI and the SAT in eastern China}

Figure 3 shows the time series of the original and low-pass filtered EASMI and SATI in eastern China. Both EASMI and SATI exhibit considerable interannual and interdecadal variability. The correlation coefficient between two indices is 0.03 and -0.06 in the original and low-pass filtered series during the whole time period. However, when we focused on the time period of 1960-2004, the correlation coefficient became 0.31 (significant at 0.05 level) and -0.16 , respectively. It implies the correlation between the EASMI and the SATI in eastern China exhibits an opposite relationship on interannual and decadal time scales during 1960-2004.
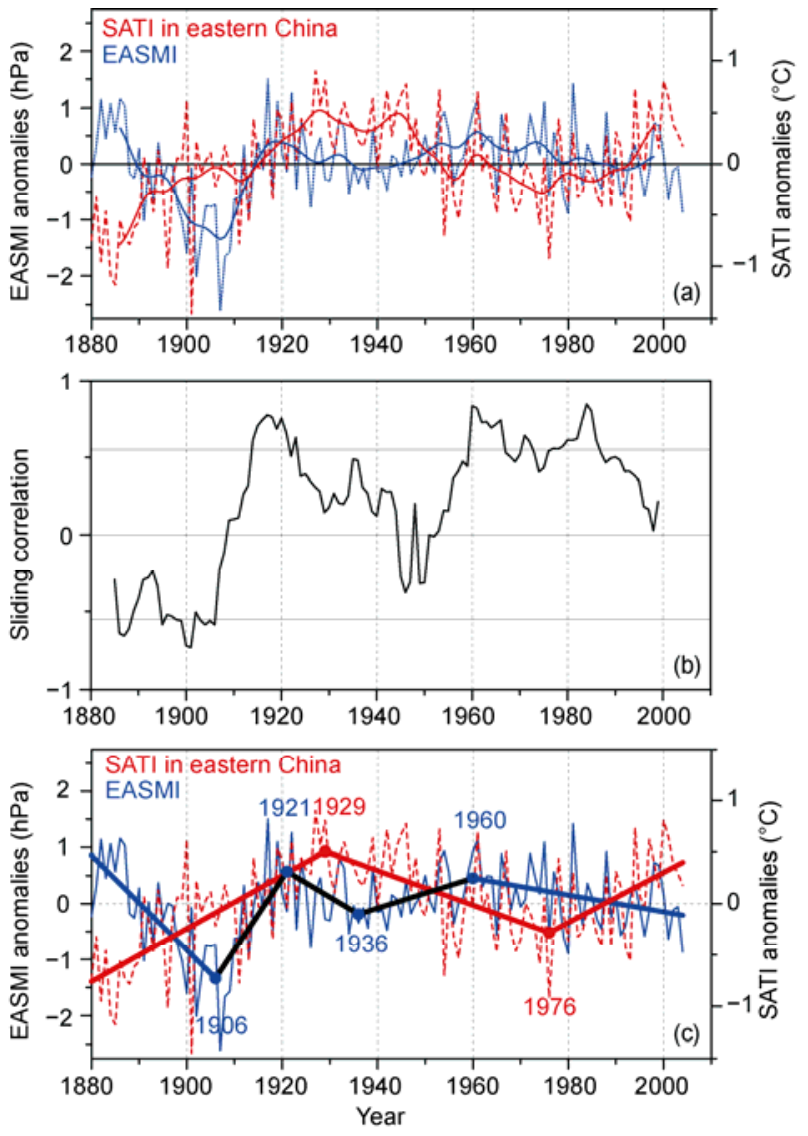

Figure 3 Time series of EASMI (blue) and summer SAT index (SATI, red) anomalies in the eastern China during 1880-2004. (a) The original (dash line) and the low-pass filtered time series (thick solid lines); (b) 11-year sliding correlation between the EASMI and summer SATI (two solid lines parallel to the $x$-axis indicate the criteria with 0.05 significant level); (c) the original series and the decadal trends of EASMI and SATI defined by the PLF, respectively. The dots and values indicate the breakpoints in the time series of the EASMI and the SATI. 
In order to further identify the decadal relationship between EASMI and SATI, we applied an 11-year sliding correlation to the time series (Figure 3(b)). It is found that the correlation coefficient is negative during 1880-1908 and 1945-1952, and it shows a positive correlation during 1908-1945 and 1952-2004. The period of positive correlation (more than 80 years) is longer than that of negative correlation (about 30 years). According to Figure 1(b), the EASMI is positively correlated with the SAT in the central eastern China, which implies that the decreased (increased) SLP is closely related to the increased (decreased) SAT in summer.

We applied the method of PLF to the time series of EASMI and the SATI, and calculated their linear trend on decadal time scale (named by decadal trend). The decadal trend is defined as the linear trend between the neighboring breakpoints (mostly at the peak or bottom of the low-pass signals) (Figure 3(c)). It is found that there are four breakpoints in the EASMI (1906, 1921, 1936 and 1960) and two breakpoints in the SATI (1929 and 1976). Therefore, there are two enhanced time periods of EASMI during 19061921 and 1936-1960, and three weakening periods of EASMI during 1880-1906, 1921-1936 and 1960-2004. Two warming trend periods are during 1880-1929 and 1976-2004, one cooling trend during 1929-1976. It can be seen that the EASMI and SATI show opposite trends during 1880-1906, 1921-1929, 1936-1960 and 1976-2004. In contrast, the same trends occurred during 1906-1921, 1929-1936 and 1960-1976. Obviously there is no deterministic linkage between the decadal trends of EASMI and SATI. During the time period when the EASMI and SATI shows the opposite decadal trends (Figure 3(b) and (c)), their sliding correlation coefficient is negative (i.e. during 1880-1906 and 1945-1952) or the coefficient sharply decrease (during 1921-1929 and 1976-2004). The correspondence is not accurate at the beginning and ending of time series due to the sliding effect, but one still can observe that the relationship between EASMI and SATI was greatly affected by their decadal trends as previous study.

Qian et al. [31] suggests that the climate pattern of "wetnorth and dry-south" in eastern China and cool period in China is generally associated with the strong summer monsoon, and the "dry-north and wet-south" in eastern China and a warm period in China and globe are associated with the weaker summer monsoon. Such a result suggests the decadal relationship between the EASMI and the SAT in eastern China. However, the aforementioned results suggest the decadal relationship between EASMI and the SAT in eastern China is much more complex.

\section{Decadal change of surface temperature in Asia-Pacific}

The change of East Asian winter monsoon related surface air temperature in boreal winter has been greatly affected by the high-latitude atmospheric oscillation [32,33]. In this work, we found the change of EASMI-related summer surface temperature exhibits quite complex characteristics (Figure 1(b)). We found two positive centers in the central eastern China (Region I) and east of Philippine in the North western Pacific (Region II), and two negative centers in Southeast Japan (Region III) and north Asian continent around the Lake Baikal (Region IV). The change of surface temperature in Region I and III implies the impact of subtropical thermal contrast in the EASM, which implies that the warmer (colder) SAT and lower (higher) SLP anomalies dominate the subtropical land and sea, corresponding to stronger (weaker) EASM. The change of temperature in Region II is consistent to the thermal condition in the western Pacific warming pool [34] and the change near Lake Baikal is related to the recent global warming [6]. The change of surface temperature in Region II and IV may indicate the impact of meridional thermal contrast on the EASM.

Figure 4 shows the linear trend of SAT/SST and SLP anomalies during 1960-2004, 1936-1960, 1921-1936 and 1906-1921 corresponding to the alternative weakened and enhanced EASMI. It should be noted that a land SAT dataset of CRU Ts3.1 and a SST dataset of HadISST have been combined in this analysis. It can be seen that the linear trend of SAT/SST in these four regions shows various combinations during four time periods, which implies the complex relationships between the thermal condition in AsiaPacific and the EASM. However, the effect of SAT on the EASM should be judged by the correlation and trend analysis together. When the SAT in the region is positively (negatively) correlated with the EASM and shows a cooling (warming) trend, it implies the weakening effect of SAT on the EASMI. For example, the surface temperature in Region I, III and IV all show the weakening feature in contrast to Region II during 1960-2004 when the EASMI exhibits a weakening trend.

Recent studies suggest that the decadal change of EASM can be attributed to the global scale thermal forcing [35], and it is also closely associated with the change of AsiaPacific Oscillation [36]. However, we noted that the SAT exhibits an obvious warming (cooling) trend over the Lake Baikal during 1960-2004 (1936-1960), and the reduced temperature gradients near the Lake Baikal may weaken the northern part of EASM [6]. Our results show a clear decadal relationship between the SAT in this region and EASM. Therefore, the decadal trend of SAT near the Lake Baikal also plays an important role in the decadal change of the EASM before 1960.

\section{Summary}

In the present study, we calculated the SLP-based EASMI 

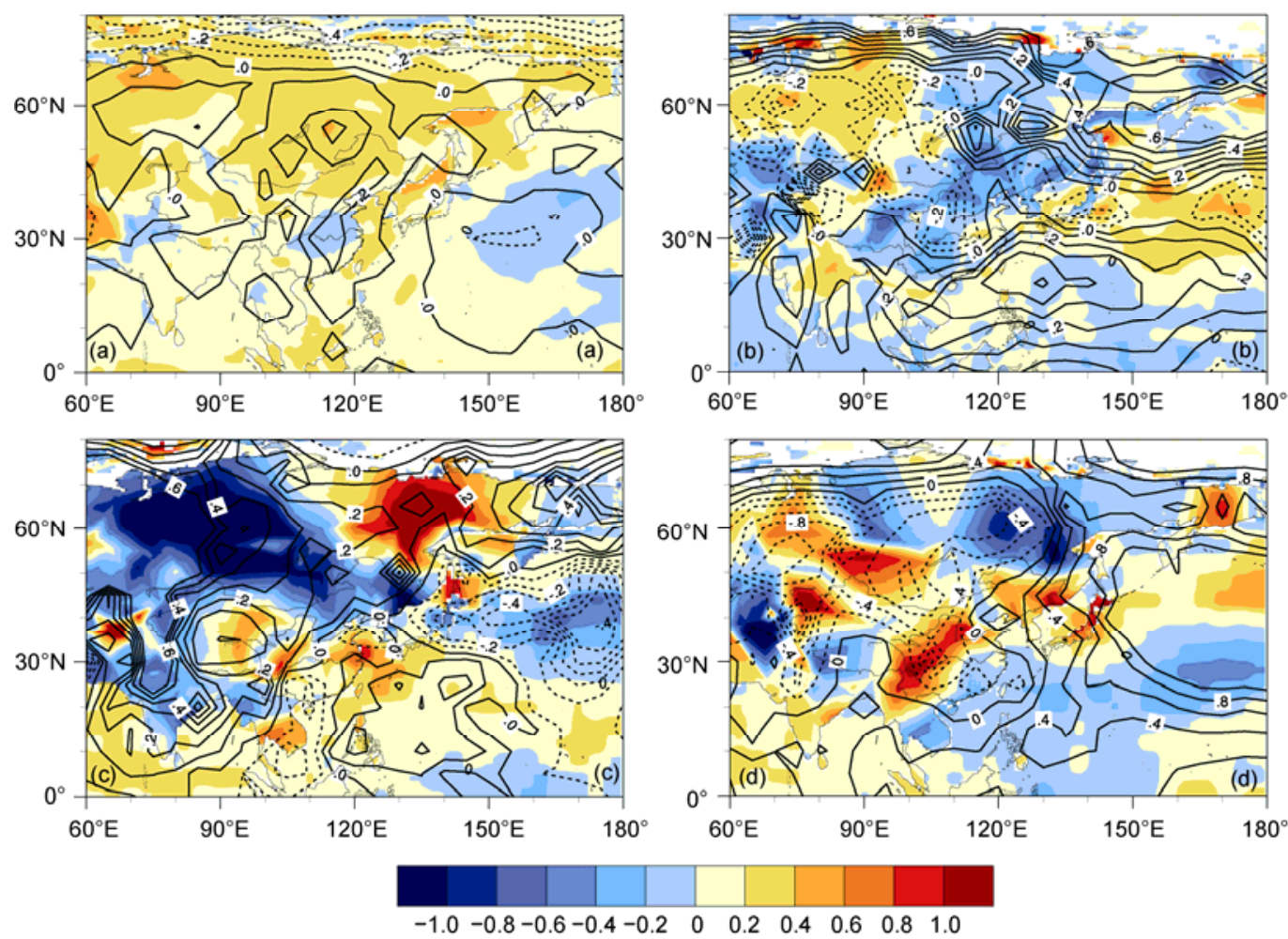

Figure 4 The linear trends of the summer SAT/SST (shaded, unit: ${ }^{\circ} \mathrm{C} / 10$ a) and SLP (contour, unit: hPa/10 a) during (a) 1960-2004, (b) 1936-1960, (c) 1921-1936 and (d) 1906-1921. The SAT and SST is derived from a global surface temperature dataset of CRU Ts3.1 and a global sea surface temperature dataset of HadISST, respectively.

with multiple SLP datasets and discussed the decadal variability of the EASM and its relation with the surface temperature in eastern China and Asia-Pacific regions during 1880-2004. The SLP in the NCEP/NCAR, ERA-40, HadSLP2 and 20CR have been evaluated with the station-observed SLP around the longitude of $110^{\circ} \mathrm{E}$ in China. We found that the HadSLP2 exhibits the best quality for its higher correlation and less deviation with the observed SLP on both annual and decadal scale during 1960-2004.

The IPCC report suggests that the EASMI has shown a marked decadal variability before the 1940s and a weakening trend since the 1920s [11]. However, in our results, it shows noticeable decadal variability since the 1920s, instead of the weakening trend as described by the IPCC report [11]. Therefore, the SLP errors in the Asian continent may result in errors in the previous result. A multi-scale $F$-test suggests that the amplified variability of EASMI before the 1940s might be attributed to the fewer sample sizes of HadSLP2, which implies that the amplitude of EASMI before and after the 1940s is not comparable.

The 11-year running correlation analysis indicates that there is positive correlation between the EASMI and summer SATI in eastern China during $2 / 3$ of the time span of 1880-2004, implying the impact of subtropical land-sea thermal contrast on the EASMI. The PLF-based analysis implies that there are three increasing and two decreasing periods of the EASMI, as well as two increasing periods and one decreasing period of the SAT in eastern China during 1880-2004. Meanwhile, the transition of the decadal trends of the EASMI and SATI in eastern China did not occur concurrently. During the time period when the EASMI and SATI show opposite decadal trend, we found the correlations between EASMI and SAT in eastern China are negative or decreased sharply. In contrast, the correlation was positive or increased sharply for the other periods. In addition, we found the EASMI-related change of SAT mainly occurred in the central eastern China, southeast of Japan, North Asia near the Lake Baikal, and the east of the Philippines in the northwestern Pacific. Evidence shows that the thermal condition (SAT/SST) in these regions shows combined impacts on the decadal change of EASM. However, our results show the opposite decadal relationship between the SAT around the Lake Baikal and EASM. Therefore, the decadal change of SAT near the Lake Baikal also plays an important role in the linear trend of EASM before 1960.

Thanks for the editors and three anonymous reviewers for the comments and suggestions which help improve the presentation of our results. This work was supported by the National Natural Science Foundation of China (90711003, 40921003 and 40805036), the Strategic Priority Research Program-Climate Change: Carbon Budget and Relevant Issues of the 
Chinese Academy of Sciences (XDA05090408), the National Basic Research Program of China (2011FY120300) and the Basic Scientific Project of Chinese Academy of Meteorology Sciences (2013Z002).

1 Wang H J. The weakening of the Asian monsoon circulation after the end of 1970s. Adv Atmos Sci, 2001, 18: 376-386

2 Gong D Y, Ho C H. Shift in the summer rainfall over the Yangtze River valley in the late 1970s. Geophys Res Lett, 2002, 29: 71-78

3 Yu R, Wang B, Zhou T. Tropospheric cooling and summer monsoon weakening trend over East Asia. Geophys Res Lett, 2004, 31: L22212

4 Zhao P, Yang S, Yu R. Long-term changes in rainfall over Eastern China and large-scale atmospheric circulation associated with recent global warming. J Clim, 2010, 23: 1544-1562

5 Wang Y, Yan Z W, Chandler R E. An analysis of midsummer rainfall occurrence in eastern China and its relationship with large-scale warming using Generalized Linear Models. Inter J Climatol, 2010, 30: $1826-1834$

6 Zhu C W, Wang B, Qian W H, et al. Recent weakening of northern East Asian summer monsoon: A possible response to global warming. Geophys Res Lett, 2012, 39: L09701

7 Guo Q Y. The summer monsoon intensity index in East Asia and its variation (in Chinese). Acta Geogr Sin, 1983, 3: 207-217

8 Shi N, Zhu Q G. Summer monsoon index and its relationship with temperature and precipitation over east China. Inter J Climatol, 1996, 16: 757-764

9 Guo Q Y, Cai J N, Shao X M, et al. Interdecadal variability of East Asian summer monsoon and its impact on the climate of China (in Chinese). Acta Geogr Sin, 2003, 4: 569-576

10 Guo Q Y, Cai J N, Shao X M, et al. Studies on the variations of East Asian Summer Monsoon during AD 1873-2000 (in Chinese). Chin J Atmos Sci, 2004, 28: 206-215

11 Solomon S, Qin D, Manning M, et al. Climate change 2007: The physical science basis. Contribution of Working Group I to the Fourth Assessment Report of the Intergovernmental Panel on Climate Change. Cambridge: Cambridge University Press, 2007. 297

12 Yan Z W, Petit M N. On the relationship between global thermal variation and the wet/dry alterations in the asian and african monsoon areas (in Chinese). Acta Geogr Sin, 1995, 50: 471-479

13 Wang S W, Gong D Y, Zhu J H. Twentieth-century climatic warming in China in the context of the Holocene. Holocene, 2001, 11: 313321

14 Kalnay E, Kanamitsu M, Kistler R, et al. The NCEP/NCAR 40-year reanalysis project. Bull Amer Meteorol Soc, 1996, 77: 437-471

15 Uppala S M, KAllberg P W, Simmons A J, et al. The ERA-40 reanalysis. Quart J Roy Meteor Soc, 2005, 131: 2961-3012

16 Allan R, Ansell T. A new globally complete monthly historical gridded mean sea level pressure dataset (HadSLP2): 1850-2004. J Clim, 2006, 19: 5816-5842

17 Compo G P, Whitaker J S, Sardeshmukh D, et al. The twentieth century reanalysis project. Quart J Roy Meteor Soc, 2011, 137: 1-28

18 Wang S W, Zhao Z G, Li W J. Atlas of Seasonal Temperature and Precipitation Anomalies over China (1880-2007) (in Chinese). Bei- jing: China Meteorological Press, 2009. 1-273

19 Mitchell T D, Jones P D. An improved method of constructing a database of monthly climate observations and associated high-resolution grids. Int J Climatol, 2005, 25: 693-712

20 Rayner N A, Parker D E, Horton E B, et al. Global analyses of sea surface temperature, sea ice, and night marine air temperature since the late nineteenth century. J Geophys Res, 2003, 108: 4407

21 Tomé A R, Miranda M A. Piecewise linear fitting and trend changing points of climate parameters. Geophys Res Lett, 2004, 31: L02207

22 Shi X H, Xu X D. Regional characteristics of the interdecadal turning of winter/summer climate modes in Chinese mainland. Chin Sci Bull, 2007, 52: 101-112

23 Jiang J M, Mendelssohn R, Schwing F, et al. Coherency detection of multiscale significant changes in historic Nile flood levels. Geophys Res Lett, 2002, 29: 1271-1275

24 Zhu C W, He J H, Wu G X. East Asian monsoon index and its interannual relationship with large-scale thermal dynamic circulation. Acta Meteorol Sin, 2000, 58: 391-402

25 Li J P, Zeng Q C. A new monsoon index and the geographical distribution of the global monsoons. Adv Atmos Sci, 2003, 20: 299-302

26 Huang G. An index measuring the interannual variation of the East Asian summer monsoon-The EAP index. Adv Atmos Sci, 2004, 21: 41-52

27 Wang B, Wu Z W, Li J P, et al. How to measure the strength of the East Asian Summer Monsoon. J Clim, 2008, 21: 4449-4463

28 Yang S, Lau K M, Kim K M. Variations of the east Asian jet stream and Asian-Pacific-American winter climate anomalies. J Clim, 2002, 15: 306-325

29 Inoue T, Matsumoto J. A comparison of summer sea level pressure over east Eurasia between NCEP-NCAR reanalysis and ERA- 40 for the period of 1960-1999. J Meteorol Soc Jpn, 2004, 82: 951- 958

30 Wu R G, Kinter J L, Kirtman B P. Discrepancy of interdecadal changes in the Asian region among the NCEP/NCAR reanalysis, objective analyses and observations. J Clim, 2005, 18: 3048-3067

31 Qian W H, Lin X, Zhu Y F. Global and China temperature changes associated with the inter-decadal variations of East Asian summer monsoon advances. Chin Sci Bull, 2012, 57: 3923-3930

32 Wang D X, Wang C Z, Yang X Y, et al. Winter Northern Hemisphere surface air temperature variability associated with the Arctic Oscillation and North Atlantic Oscillation. Geophys Res Lett, 2005, 32: L16706

33 Bai X Z, Wang J, Liu Q Z, et al. Severe ice conditions in the Bohai Sea, China, and mild ice conditions in the Great Lakes during the 2009/10 Winter: Links to El Niño and a strong negative Arctic Oscillation. J Appl Meteorol Climatol, 2011, 50: 1922-1935

34 Huang R H, Sun F Y. Impacts of the tropical western Pacific on the East Asian summer monsoon. J Meteorol Soc Jpn, 1992, 70: 243256

35 Wang B, Liu J, Kim H J, et al. Recent change of the global monsoon precipitation (1979-2008). Clim Dyn, 2012, 39: 1123-1135

36 Zhao P, Wang B, Zhou X J. Boreal summer continental monsoon rainfall and hydroclimate anomalies associated with the Asian-Pacific Oscillation. Clim Dyn, 2012, 39: 1197-1207

Open Access This article is distributed under the terms of the Creative Commons Attribution License which permits any use, distribution, and reproduction in any medium, provided the original author(s) and source are credited. 